\title{
DYNAMIC SIMULATION MODEL FOR PRODUCTION AND DRY MATTER ACCUMULATION IN PEANUT
}

\author{
Lei Xu ${ }^{1}$, Peiling Yang ${ }^{1, *}$, Shumei Ren ${ }^{1}$, Tao Zhang ${ }^{2}$, Yuguo Han ${ }^{1}$ \\ ${ }^{1}$ College of Water Conservancy \& Civil Engineering China Agricultural University, Beijing \\ 100083, China \\ ${ }^{2}$ Institute of Low Energy Nuclear Physics Beijing Normal University, Beijing 100875, China \\ * Corresponding author, Address: College of Water Conservancy \& Civil Engineering China \\ Agricultural University,Beijing 100083, China, Tel: +86-10-62737866, Fax: +86-10-6273 \\ 6911,Email: yang-pl@163.com
}

\begin{abstract}
On the base of the physiological processes and according to the balance of the carbon, a simulation model for photosynthetic production and dry matter accumulation was established for the peanut. The photosynthesis rate of unit green leaf area was scribed by negative exponential function. By analyzing the characteristic of the shoots, the Gaussian integration method was used to calculate the photosynthesis for each period of time, and the daily total canopy photosynthesis which was that of all day. The effects of physiological age, temperature and water deficit factors on maximum photosynthesis rate were adequately quantified. The maintenance respiration and growth respiration was considered in the model which consume some photosynthetic. The computer was used to simulate the progress. The model was tested for dry matter accumulation by the field experiments of different genotypes and water levels and the results showed a good fit between the observed and simulated data. The present model appears to be favorable on mechanism explanation and reliable prediction.
\end{abstract}

Keywords: Peanut; Photosynthesis; Dry matter accumulation; Simulation model

Please use the following format when citing this chapter:

Xu, L., Yang, P., Ren, S., Zhang, T. and Han, Y., 2009, in IFIP International Federation for Information Processing, Volume 293, Computer and Computing Technologies in Agriculture II, Volume 1, eds. D. Li, Z. Chunjiang, (Boston: Springer), pp. 245-252. 


\section{INTRODUCTION}

Using the information technology to simulate the growth situation of the crops is a new research field and springs up in the last thirty or forty years. It combines the information technology and the agricultural technology and brings a profound and extensive influence to the traditional agricultural technology and production. Crop growth simulation is a synthetical and basic research field; it includes agronomy, aerography, botany and agrology and so on. The simulation model is the research keystone of this subject (Wang Yali etal, 2005). The mechanism, system and currency are its characters. Researchers for China or abroad have done lot of work in this way at present especially the Netherlandish and the American scholars(de Wit C.T. etal, 1970; Ritchie J.T.,1972; de Wit C.T. etal, 1978; van Keulen H, 1982; Ritchie J.T.,1997; Yan Lijiao etal, 1998).

Peanut is usually planted as oil and economic plants, so the growth area is small and the growth region is narrow in a certain extent. And this situation leads to people do little research in the model simulation of peanut(Duncan etal,1974; Young etal,1979; Ingram etal,1981). Compared with wheat, rice and so on, the research did in China was also little, but in China peanut plays an important role in the economic development and agricultural production. So on the base of the work has done in China and abroad, the simulation on peanut was did. In this project, the radicalization, temperature, moisture and other factor were all considered synthetically. The relation ship between the photosynthesis rate and circumstance was affirmed; the parameter in this model was selected. The dry matter accumulation model was set fit to the climate of China.

\section{MATERIAL AND METHOD}

\subsection{Experimental place}

The peanut was planted in the southeast area of Pangge village in Daxing district of Beijing. The soil type of this area was sandy loam. The average dry density was $1.38 \mathrm{~g} / \mathrm{cm}^{3}$ : the total nitrogen was $0.058 \%$; the average $\mathrm{N}, \mathrm{P}$, $\mathrm{K}$ contents were $0.005 \%, 0.002 \%$ and $0.013 \%$ separately; the soil organic matter content was $0.95 \%$. Hence this land was suitable to plant peanuts. 


\subsection{Experimental design}

The field blocks were designed by two factors; one was the soil water condition and the other was breed. To reach the designed water conditions, the blocks were covered with plastic shed when it rained at the stages of flowering and pod-setting during peanut growth. To prevent water diffuse, plastic membranes were buried surrounding each plot for $2 \mathrm{~m}$ in depth. The seeds were planted in the middle of May in 2006 and harvested in the middle of September. The size of each sub plot was $2.1 \mathrm{~m} \times 2.0 \mathrm{~m}$, and repeated 3 times. The seeding method was hill-drop. The hill spacing was $20 \mathrm{~cm}$, row spacing was $35 \mathrm{~cm}$.

\section{MODEL ESTABLISH}

\subsection{Calculate of the total radiation}

Based on the equation of Angstron, according the percent of sunlight, the quantity of radiation was got, and it was input to the model as the primal variable. The expression was followed as this:

$$
\left.Q(t)=Q_{0}(t) \times\left[a+b \times \frac{d S U N H}{D L(t)}\right)\right]
$$

Parameter meaning: $\mathrm{Q}(\mathrm{t})$-the numerical value of total radiation $\left(\mathrm{Jm}^{-2} \mathrm{~d}^{-1}\right)$; Q0 (t)-the numerical value of chronometer radiation; dSUNH-the sunlight hour(h); DL ( $\mathrm{t}$ )-length of daytime; a and $b$-the parameter of mode.

\subsection{The calculation of available radiation in the shoots}

Use the method of Gauss integral to calculate daily available radiation, the particular calculational expressions was below:

$P A R[i]=0.5 \times Q(t) \times \operatorname{SINB}[i] \times(1.0+0.4 \times \operatorname{SINB}[i]) / D \operatorname{SINBE}$

Parameter meaning: PAR[i]-the available radiation in the $i$ time $\left(\mathrm{Jm}^{-2} \mathrm{~s}^{-1}\right)$; SINB[i]-the sine value of altitude solar; Th[i]-the sun time(h); DIS[i]-the distance in Gauss equation. 


\subsection{The distribute and absorb of the sunlight in the shoot}

On the suppose of the leaves were all equality medium and with the formula of Lambert-Beer(Marcelis L.F.M.,1998)in1953 and Monsi-Seak formula(Penning de Vries,1982) the available radiation in the shoots can be got:

$$
I_{L}[i]=(1-\rho[i]) \times P A R \quad[i] \times e^{-K[i] \times L A I}
$$

Parameter meaning: K[i]-the extinction coefficient of the shoot; $\rho[\mathrm{i}]-$ the reflectivity rate of the shoot; LAI- the index of the leaf area.

\subsection{The establish of the photosynthesis model}

Use minus exponential model to express the single leaf photosynthesis

$$
P S[i]=P_{a \max } \times\left[1-E X P\left(-E F F \times I_{l}[i] / P_{a \max }\right)\right]
$$

Parameter meaning: PS[i]- the photosynthesis rate of single leaf $\left(\mathrm{kgCO}_{2} \mathrm{hm}^{-2} \mathrm{~h}^{-1}\right)$; Pamax-the maximum photosynthesis rate of single leaf $\left(\mathrm{kgCO}_{2} \mathrm{hm}^{-2} \mathrm{~h}^{-1}\right)$; EFF-the primal utilize efficiency of the sunlight; II[i]- the available radiation that absorbed in the $\mathrm{i}$ time.

The affect of temperature

Based on the existence research result (Liu Tiemei etal,2003), the sine function was use to correct the photosynthesis model:

$$
f(T)=\left\{\begin{array}{lc}
0 & T<T_{0} \text { or } T>T_{\max } \\
\sin \left[\left(T-T_{0}\right) /\left(T_{o l}-T_{0}\right) \times \pi / 2\right] & T_{0} \leq T \leq T_{o l} \\
1 & T_{o l} \leq T \leq T_{o u} \\
\cos \left[\left(T-T_{\text {ou }}\right) /\left(T_{\max }-T_{\text {ou }}\right) \times \pi / 2\right] & T_{\text {ou }} \leq T<T_{\max }
\end{array}\right.
$$

Parameter meaning: T-the daily temperature $\left({ }^{\circ} \mathrm{C}\right)$; T0-the basic temperature $\left({ }^{\circ} \mathrm{C}\right)$; T01-the floor level of optimum temperature $\left({ }^{\circ} \mathrm{C}\right)$; Tou-the upper limit of optimum temperature $\left({ }^{\circ} \mathrm{C}\right)$; Tmax- the maximum temperature $\left({ }^{\circ} \mathrm{C}\right)$.

The affect of water

Usually the soil water content will change with the variety of rainfall, evaporation and soil factor, so the photosynthesis model should be amended (Liu Tiemei etal,2001; Jiang Qingzhen etal,1999):

$$
f(W)=\left\{\begin{array}{cc}
W_{t}<W_{p} \\
\left(W_{t}-W_{p}\right) /\left(W_{2}-W_{p}\right) & W_{p} \leq W_{t} \leq W_{2} \\
1 & W_{2} \leq W \leq W_{3} \\
0.5+0.5\left(W_{t}-1\right) /\left(W_{3}-1\right) & W_{t}>W_{3}
\end{array}\right.
$$

Parameter meaning :Wt-the average soil water constant of $0-80 \mathrm{~cm} ; \mathrm{W}_{\mathrm{p}^{-}}$ Wilting Point; $\mathrm{W}_{2}$-the floor level of optimum water; $\mathrm{W}_{3}$-the upper limit of optimum water.

The affect of physiological age 
The formula to calculate the affect of physiological age was as follow:

$$
f(A)=\left\{\begin{array}{ccc}
1 & P D T \leq 28 \\
\operatorname{EXP}[-\lambda \times(P D T-28)]) & P D T>28
\end{array}\right.
$$

Parameter meaning: PDT-the number of growth days of peanut; $\lambda$-the coefficient of the curve.

The instantaneous photosynthesis speed of total shoots

$$
\text { TPS }[i]=P S[i] \times L A I
$$

Parameter meaning: TPS[i]-The instantaneous photosynthesis speed of total shoots $\left(\mathrm{kgCO}_{2} \mathrm{hm}^{-2} \mathrm{~h}^{-1}\right)$

The daily photosynthesis speed of total shoots

$$
D T G A=\left[\left(\sum_{i=1}^{3} T P S \quad[i] \times W G U S S \quad[i]\right)\right] \times D L
$$

\subsection{Respiration of the shoot}

The model of photorespiration

$$
R P=D T G A \times R_{p}\left(T_{0}\right) \times Q_{10}^{\frac{T-T_{0}}{10}}
$$

The model of dark-respiration

Consult the research result of Penning de Vries, Marcelis (Marcelis L. F.,1993; Marcelis L.F.M) abroad and W X Cao, T M Liu, H J Wang in China, the dark-respiration was calculated:

$$
R D=R G+R M
$$

Parameter meaning: RD-dark-respiration consumption $\left(\mathrm{kgCO}_{2} \cdot \mathrm{hm}^{-2} \cdot \mathrm{d}^{-1}\right)$; RG-growth respiration $\left(\mathrm{kgCO}_{2} \cdot \mathrm{hm}^{-2} \cdot \mathrm{d}^{-1}\right)$; RM- maintenance respiration $\left(\mathrm{kgCO}_{2} \cdot \mathrm{hm}^{-2} \cdot \mathrm{d}^{-1}\right)$.

(a) The calculate of $\mathrm{RM}\left(\mathrm{kgCO}_{2} \cdot \mathrm{hm}^{-2} \cdot \mathrm{d}^{-1}\right)$

$$
R M=R_{m}\left(T_{0}\right) \times Q_{10}^{\frac{T-T_{0}}{10}} \times W(t)
$$

(b) The calculate of RG $\left(\mathrm{kgCO}_{2} \cdot \mathrm{hm}^{-2} \cdot \mathrm{d}^{-1}\right)$

$$
R G=R_{g} \times(D T G A-R M)
$$

\subsection{The dry matter accumulation model}

With the balance of photorespiration and dark-respiration, the crop grown Based on the principle of conservation of mass and conservation of energy, the daily total photosynthesis was calculated: 


$$
\begin{aligned}
& P N \\
& (14)
\end{aligned}
$$

Parameter meaning: PN- the daily total photosynthesis $\left(\mathrm{kgCO}_{2} \cdot \mathrm{hm}^{-2} \cdot \mathrm{d}^{-1}\right)$.

$$
\Delta W=\lambda \times \beta \times P N /(1-\varepsilon)
$$

Parameter meaning: $\Delta \mathrm{W}$-the increment of daily dry matter $\left(\mathrm{kgm}^{-2} \mathrm{~d}^{-1}\right)$; $\lambda, \beta, \varepsilon$-the coefficient.

The expressions of dry matter accumulate of the peanut:

$$
W(t+1)=W(t)+\Delta W
$$

\section{THE PRIMARY TEST OF MODEL}

Five breed of peanut and two water condition were used to test the model. Take the RMSE and RE way to test the gap between the simulated value and observational value. The detail value was shown in table 1 .

Table1 The compare between simulated value and observational value

\begin{tabular}{ccccccc}
\hline \multirow{2}{*}{ Treatment } & \multirow{2}{*}{$\begin{array}{c}\text { water } \\
\text { condition }\end{array}$} & $06-6-21$ & $06-7-6$ & $06-8-4$ & $06-8-28$ & $06-9-14$ \\
\cline { 3 - 7 } & & & & RE & & \\
\hline \multirow{2}{*}{ Treatment I } & normal & 4.36 & 1.29 & 0.5 & 0.04 & 0.11 \\
& stress & 4.99 & 0.85 & 0.11 & 0.05 & 0.06 \\
Treatment II & normal & 1.87 & 0.8 & 0.43 & 0.10 & 0.14 \\
& stress & 3.13 & 0.50 & 0.18 & 0.08 & 0.06 \\
TreatmentIII & normal & 0.57 & 0.19 & 0.22 & 0.19 & 0.24 \\
& stress & 3.31 & 0.24 & 0.21 & 0.10 & 0.09 \\
TreatmentIV & normal & 2.25 & 1.21 & 0.46 & 0.02 & 0.02 \\
& stress & 3.70 & 0.97 & 0.17 & 0.02 & 0.00 \\
\multirow{2}{*}{ CK } & normal & 0.75 & 0.34 & 0.04 & 0.21 & 0.22 \\
& stress & 2.61 & 0.30 & 0.34 & 0.22 & 0.16 \\
average RE & normal & 1.96 & 0.77 & 0.33 & 0.11 & 0.15 \\
& stress & 3.55 & 0.57 & 0.20 & 0.09 & 0.07 \\
\multirow{2}{*}{ RMSE } & normal & 399.89 & 142.66 & 97.78 & 72.14 & 69.46 \\
& stress & 506.26 & 117.77 & 67.47 & 72.20 & 73.30 \\
\hline
\end{tabular}

Seen from table 1, the maximum average RE under the normal water condition and the stress condition was 1.96, and the RMSE was little than $399.89 \mathrm{~kg} / \mathrm{hm}^{-2}$. The maximum average RE under the stress condition was 3.55 , and the RMSE was little than $506.26 \mathrm{~kg} / \mathrm{hm}^{-2}$. The data were also showed that, when used this model to simulate the accumulate process of the peanut; the error was bigger in the early period than in the following period. With days going on the error became small gradually.

The equation of $\mathrm{y}=\mathrm{x}$ in figure 1 means that the simulated value and were totally accord. So the near the distance of the point to the line, the small of the error was. 


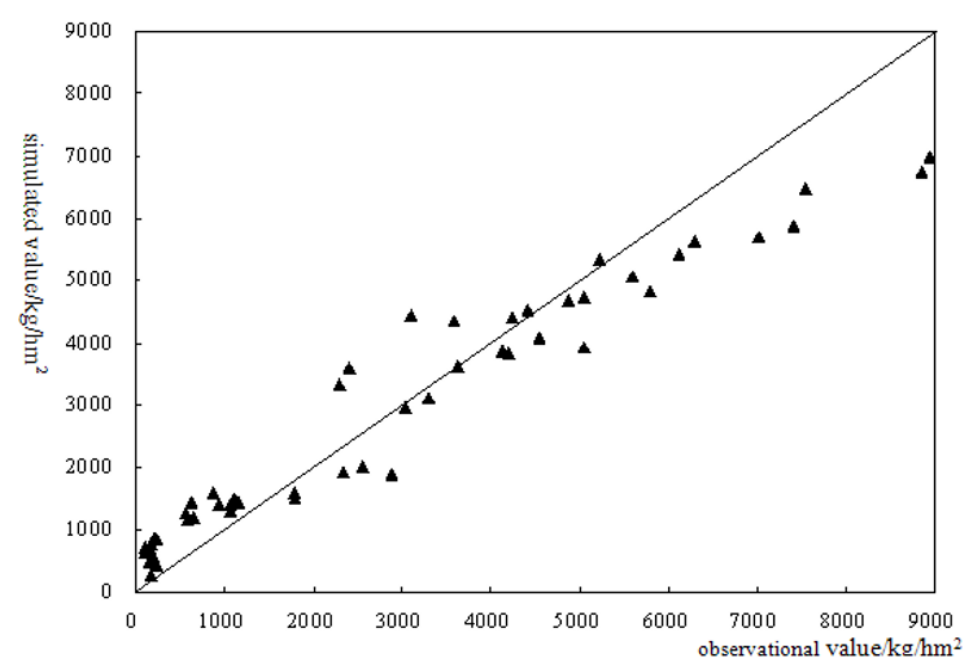

Fig. 1 Compare of the observational value and the simulated

Results of table 1 and figure 1 showed that in the early age of the peanut the error was large, but through the whole growth period, the model can simulate the simulation process of the dry matter exactly. This model had preferable forecast and applicability.

\section{CONCLUSIONS}

Based on the conservation of mass, conservation of energy, aerography and botany, the dry matter accumulation model of peanut was found. The results showed that this model had preferable forecast and applicability. Compared with the peanut simulation model before, this model had advanced in the following ways. Firstly, the Gaussian integration method was used to calculate the photosynthesis for each period of time, and the daily total canopy photosynthesis which was that of all day. Secondly, the effects of physiological age, temperature and water deficit factors on maximum photosynthesis rate were adequately quantified. Thirdly, by analyzing the characteristic of the shoots, the maintenance respiration and growth respiration was considered in the model. Tested by the field experiments of different genotypes and water levels in 2006, the results showed a good fit between the observed and simulated data. The present model appears to be favorable on mechanism explanation and reliable prediction. 


\section{ACKNOWLEDGMENT}

Financial supports from China Financially Supporting Transforming Achievements of Agricultural Science and Technology (05EFN217100425) were highly appreciated

\section{REFERENCES}

De Reffye Ph., Houllier F. Modeling plant growth and architecture: some recent advances and applications to agronomy and forestry. Current Science. 1997,73 (11):984-992

De Wit C.T., Brouwer R, Penning de Vries F. W. T. The simulation of photosynthetic systems. In:Setlik I (ed.).Prediction and Management of photosynthetic productivity. Proceedings of the International Biological Program/Plant Production Technical Meeting, 1970:47-70

De Wit C.T.,et al. Simulation of assimilation, respiration and transpiration of crops. Simulation Monographs, 1978

Duncan, W.G. PENUTZ: A Simulation Model for Predicting Growth. Development and Yield of A Peanut Plant. Prec. of APREA. 1974, 6:72

Ingram, K.T., D.E. McCloud, etal. PNUTMOD: An Educational Model of Crop Growth and Development Simulation in A Handheld Calculator. Journal of Agron. Education.1981, 10:5-13

Jiang Qingzhen,Zhang Jianping,Li Yanming. Preliminary Study on the Simulation Model of Water Effect on Biomass Production of Winter Wheat. Journal of Agricultural University of Hebei, 1999,22(2):27-31

Liu Tiemei, Cao Cougui, Huang Yong, etal. A Simulation Model of Photosynthetic Production and Dry Matter Accumulation in Rapeseed. Journal of Huazhong Agricultural University, 2003, 22(6): 533-537

Liu Tiemei, Cao Weixing,Luo Weihong, etal. A Simulation Model of Photosynthetic Production and Dry Matter Accumulation in Wheat. Journal of Triticeae Crops, 2001,21(3):26-31

Marcelis L F M.Simulation of biomass allocation in glasshouse cropsa review.Acta Horticulturae.1993,328:49 67

Marcelis L.F.M. Fruit growth and biomass allocation to the fruits in cucumber I. Effect of fruit load and temperature. Sci. Hort. 1993, 54(2): 107-121 